\title{
INHIBITION OF CHOLINESTERASES BY WATER-SOLUBLE PALM FRUIT EXTRACT
}

\author{
SOON-SEN LEOW*; SYED FAIRUS* and RAVIGADEVI SAMBANTHAMURTHI**
}

\begin{abstract}
Cholinesterase (ChE) inhibitors are used for the symptomatic treatment of Alzheimer's disease and other neurological pathologies. There is interest in developing new ChE inhibitors from natural plant compounds. Water-Soluble Palm Fruit Extract (WSPFE) recovered from the aqueous oil palm vegetation liquor is rich in phenolic acids and has potential neuroprotective effects. Here, we investigated the effects of WSPFE samples on acetylcholinesterase (AChE) and butyrylcholinesterase (BChE). WSPFE ethyl acetate fraction (EAF) inhibited these enzymes the most ( $A C h E I C_{50}: 0.218 \pm 0.029 \mu \mathrm{g} \mathrm{ml} l^{-1} ; B C h E I C_{50}: 222.860 \pm 5.777$ $\mu \mathrm{g} \mathrm{ml^{-1 }}$ ) and had the highest AChE selectivity index (SI) value (1022.294) compared to whole samples and seven individual fractions but these effects were weaker than those of the AChE selective agent donepezil hydrochloride (DH) (AChE IC ${ }_{50}: 0.013 \pm 0.001 \mu^{g} \mathrm{ml}^{-1}$; BChE IC ${ }_{50}: 19.820 \pm 1.415 \mu \mathrm{g} \mathrm{ml} \mathrm{l}^{-1}$; AChE SI: 1524.615). Fractions containing $\mathrm{p}-$ hydroxybenzoic acid and protocatechuic acid had the lowest AChE SI values (7.584 and 9.367 respectively) and may thus, function as dual ChE inhibitors. Binary mixtures of DH and WSPFE EAF might have more potent inhibitory effects against these enzymes, as well as higher $B C h E / A C h E$ selectivity. Further studies to investigate the ChE inhibition potential of these WSPFE samples are warranted.
\end{abstract}

Keywords: cholinesterases, neurodegenerative diseases, oil palm phenolics.

Received: 19 November 2020; Accepted: 11 March 2021; Published online: 17 June 2021.

\section{INTRODUCTION}

Neurodegeneration negatively affects mental and physical functioning in elderly people suffering from neurodegenerative diseases, such as Alzheimer's disease, Parkinson's disease, multiple sclerosis and amyotrophic lateral sclerosis. The global population suffering from Alzheimer's disease, which is the main cause of dementia, was established to be around 45 million in 2015, and this number is expected to double by 2030 and triple by 2050 (Scheltens et al.,

\footnotetext{
Malaysian Palm Oil Board,

6 Persiaran Institusi, Bandar Baru Bangi,

43000 Kajang, Selangor, Malaysia.

E-mail: ssleow@mpob.gov.my

** Academy of Sciences Malaysia, Level 20, West Wing, MATRADE Tower,

Jalan Sultan Hj. Ahmad Shah,

off Jalan Tuanku Abdul Halim,

50480 Kuala Lumpur, Malaysia.
}

2016). The cholinergic system appears to be the earliest and most affected molecular mechanism that describes Alzheimer's disease pathophysiology (Craig et al., 2011). In the cholinergic hypothesis, damage to brain nerve cells by senile plaques leads to decreases in choline transferase activities and losses in cognitive functions (Davies and Maloney, 1976). At the heart of the cholinergic system are the cholinesterase (ChE) enzymes. ChEs are enzymes splitting esters of choline (Pohanka, 2011). There are two types of ChEs, namely acetylcholinesterase (AChE) and butyrylcholinesterase (BChE).

AChE (EC 3.1.1.7), also known as true ChE, catalyses the hydrolysis of acetylcholine (ACh) into choline and acetic acid, a reaction necessary to return a cholinergic neuron to its resting state after activation. AChE is localised in the synaptic gaps of the central and peripheral nervous systems. This membrane-bound enzyme is projected into the synapse and terminates nervous 
impulses by catalysing ACh hydrolysis. AChE is known to participate in vicious cycles resulting in the aggregation of beta-amyloid plaques and neurofibrillary tangles found in Alzheimer's disease (Garcia-Ayllon et al., 2011). Strategies that increase ACh levels through the use of AChE inhibitors demonstrate symptomatic efficacy in Alzheimer's disease (Nordberg et al., 2013). In addition to dementia, AChE inhibitors are also clinically used to counteract other neurological pathologies, such as myasthenia gravis (Colovic et al., 2013). They are also used in pain management by decreasing the nociception pain response and generating analgesic actions (Eldufani and Blaise, 2019), as well as in postanaesthesia by recovering neuromuscular blockade induced by certain anaesthetics (Srivastava and Hunter, 2009).

On the other hand, BChE (EC 3.1.1.8), also known as pseudo $\mathrm{ChE}$ or plasma $\mathrm{ChE}$, catalyses the hydrolysis of the neurotransmitter butyrylcholine (BCh) into choline and butyric acid. BChE can also hydrolyse $\mathrm{ACh}$ and compensate for $\mathrm{AChE}$ when its levels are depleted. BChE accounts for up to $90 \%$ total serum ChE, while its activity is 20-fold lower than AChE in hydrolysing ACh (Arbel et al., 2014). Many studies have highlighted that BChE plays a more important role in Alzheimer's disease and selective inhibitors of BChE could be promising drug candidates (Greig et al., 2005; Nordberg et al., 2013).

The most commonly prescribed ChE inhibitors are donepezil, rivastigmine and galantamine. Among these inhibitors however, donepezil is the only ChE inhibitor approved for the treatment of all stages of Alzheimer's disease (Allgaier and Allgaier, 2014; Schneider et al., 2014). Natural plant resources possessing $\mathrm{ChE}$ inhibitory activities may potentially improve dementia and other neurodegenerative symptoms (Tundis et al., 2016). Galantamine and rivastigmine are plant-derived alkaloids (Balkrishna et al., 2019). There is also interest in developing new ChE inhibitors from among plant non-alkaloid compounds, such as polyphenols (Jabir et al., 2018; Khan et al., 2018). As such, various plant extracts have been shown to have AChE and/or BChE inhibitory activities, including those from Africa (Adewusi and Steenkamp, 2011), China (Kaufmann et al., 2016), Europe (Ferreira et al., 2006; Wszelaki et al., 2010), India (Kadiyala et al., 2014; Mathew and Subramanian, 2014; Sheeja Malar et al., 2017), Middle East (Orhan et al., 2004; Orhan et al., 2008), South America (Nino et al., 2006) and South East Asia (Kumaran et al., 2019; Nuria et al., 2020; Tappayuthpijarn et al., 2012).

The oil palm (Elaeis guineensis) is a high oilproducing tropical plant. There continues to be increasing evidence showing the potential health benefits of nutraceuticals and phytonutrients derived from the oil palm (Kushairi et al., 2019).
The water-soluble part of the oil palm fruit is rich in phenolic acids, including three caffeoylshikimic acid isomers, $p$-hydroxybenzoic acid, protocatechuic acid (Sambanthamurthi et al., 2011) and an indoleacetic acid derivative (Sambanthamurthi et al., 2014), as well as shikimic acid (Sambandan et al., 2011). Termed Water-Soluble Palm Fruit Extract (WSPFE), palm fruit bioactives (PFB), palm fruit juice (PFJ) or oil palm phenolics (OPP), these compounds could be recovered from the aqueous vegetation liquor during the palm oil milling process (Sambanthamurthi et al., 2011). WSPFE has been shown to have potential neuroprotective effects, such as reducing neuroinflammatory factors in vitro (Weinberg et al., 2018a), inhibiting beta-amyloid peptide aggregation in vitro (Weinberg et al., 2018b), up-regulating genes involved in brain development and activity in vivo (Leow et al., 2013) and increasing brain tyrosine hydroxylase levels in vivo (Weinberg et al., 2019). As such, we hypothesised that WSPFE might also have possible ChE inhibition effects in the present study.

\section{MATERIALS AND METHODS}

\section{Preparation of WSPFE Samples}

Liquid WSPFE was obtained from the Malaysian Palm Oil Board (MPOB) Phenolic Antioxidant Pilot Plant in Labu, Negeri Sembilan, Malaysia (Sambanthamurthi et al., 2008). Spray dried (SD) WSPFE was obtained through the spray drying process carried out on liquid WSPFE at Biotropics Malaysia Berhad, Shah Alam, Selangor, Malaysia. Freeze dried (FD) WSPFE was obtained by freeze drying liquid WSPFE at MPOB. WSPFE ethyl acetate fraction (EAF) was obtained by fractionating liquid WSPFE with ethyl acetate, followed by rotary evaporation and freeze drying. The remaining water partition was also collected, followed by rotary evaporation and freeze drying to obtain WSPFE water fraction (WF).

The different WSPFE fractions (F1-F7) were prepared by subjecting WSPFE EAF to preparative HPLC using a Waters Preparative AutoPurification High Performance Liquid Chromatography (HPLC) System (Waters Corporation, Milford, MA, USA). Separation was achieved by using a reverse phase Waters Atlantis C18 $5 \mu \mathrm{m}$ column (Waters Corporation, Milford, MA, USA). A binary gradient system was used as the mobile phase, with phase A comprising distilled water containing $0.02 \%$ $(\mathrm{v} / \mathrm{v})$ trifluoroacetic acid and phase B comprising 70\%:30\% (v/v) methanol-acetonitrile. A flow rate of $20 \mathrm{ml} \mathrm{min}{ }^{-1}$ and a pressure limit of $2.76 \times 10^{4} \mathrm{kPa}$ were used. The gradient elution with a total run time of 55 min was as follows: Started from $100 \%(\mathrm{v} / \mathrm{v})$ phase $A$ and $0 \%(\mathrm{v} / \mathrm{v})$ phase $B$, increased to $32.5 \%$ $(\mathrm{v} / \mathrm{v})$ phase $\mathrm{B}$ over $40 \mathrm{~min}$, then increased to $62.5 \%$ 
$(\mathrm{v} / \mathrm{v})$ phase B over $6 \mathrm{~min}$ and finally decreased to $0 \%(\mathrm{v} / \mathrm{v})$ phase B over $9 \mathrm{~min}$. Seven fractions (F1-F7) as characterised by ultraviolet/visible (UV / VIS) detection at $280 \mathrm{~nm}$ UV wavelength were collected based on their retention time.

The total phenolic content of these samples at $5000 \mu \mathrm{g} \mathrm{ml} \mathrm{m}^{-1}$ was determined in terms of $\mu \mathrm{g} \mathrm{mg^{-1 }}$ gallic acid equivalent (GAE) by using the Folin-Ciocalteu reagent (Merck, Germany) and an absorbance reading at $765 \mathrm{~nm}$ using the U-2800 spectrophotometer (Hitachi, Japan) (Gao et al., 2000). These prepared samples were stored at $-20^{\circ} \mathrm{C}$ until use.

\section{AChE Assays}

AChE assays were carried out using the commercial AChE Assay Kit (Fluorometric-Red) (ab138873) (Abcam PLC, Cambridge, United Kingdom), according to manufacturer's instructions. The kit uses AbRed Indicator to quantify the choline produced from the hydrolysis of ACh by AChE through choline oxidase-mediated enzyme coupling reactions. The fluorescence intensity of AbRed Indicator is used to measure the amount of choline formed, which is proportional to the $\mathrm{AChE}$ activity and was measured at $\mathrm{Ex} / \mathrm{Em}=$ $540 / 590 \mathrm{~nm}$ in a kinetic mode of 1-min intervals for $30 \mathrm{~min}$ using the Infinite M200 Microplate Reader (Tecan, Switzerland). WSPFE samples were tested at varying concentrations between 0 to 500 $\mu \mathrm{g} \mathrm{ml} l^{-1}$ to determine the half maximal inhibitory concentration $\left(\mathrm{IC}_{50}\right)$ values of the samples on $\mathrm{AChE}$. Negative control wells containing the substrate and enzyme without inhibitor samples, positive control wells containing the substrate, enzyme and the positive control inhibitor donepezil hydrochloride (DH) (ab120763) (Abcam PLC, Cambridge, United Kingdom) (Augustin et al., 2020; Sheeja Malar et al., 2017; Suganthy and Devi, 2016), as well as colour control samples which functioned as blanks for the corresponding samples were also prepared in these experiments.

\section{BChE Assays}

BChE assays were carried out using the commercial BChE Assay Kit (Colourimetric) (ab241010) (Abcam PLC, Cambridge, United Kingdom), according to manufacturer's instructions. The kit is based on the ability of BChE to hydrolyse a substrate and produce thiocholine. Thiocholine reacts with 5, 5'-dithiobis (2-nitrobenzoic acid) and generates a yellow chromophore that can be quantified at $412 \mathrm{~nm}$. This was measured in a kinetic mode of 1-min intervals for $30 \mathrm{~min}$ using the Infinite M200 Microplate Reader (Tecan, Switzerland). WSPFE samples were tested at varying concentrations between 0 to $500 \mathrm{\mu g} \mathrm{ml}^{-1}$ to determine the $\mathrm{IC}_{50}$ values of the samples on BChE. Negative control wells containing the substrate and enzyme without inhibitor samples, positive control wells containing the substrate, enzyme and the positive control inhibitor DH (ab120763) (Abcam PLC, Cambridge, United Kingdom), as well as colour control samples which functioned as blanks for the corresponding samples were also prepared in these experiments.

\section{Synergistic Assays Using Binary Mixtures of DH and WSPFE EAF}

To determine the potential synergistic effects of $\mathrm{DH}$ and WSPFE EAF on the inhibition of AChE and $\mathrm{BChE}$, binary-mixture experiments were performed using the assays described in the previous section. Two sets of experiments were performed, i.e. set A to identify the effects of adding $\mathrm{DH}$ on the $\mathrm{IC}_{50}$ value of WSPFE EAF, and vice versa in set B. For set A, fixed concentrations of DH used were $0.01 \mu \mathrm{g} \mathrm{ml}^{-1}$ and $20 \mu \mathrm{g} \mathrm{ml}^{-1}$ for AChE and BChE enzymatic assays respectively, chosen on the basis of the respective $\mathrm{IC}_{50}$ values. WSPFE EAF in varying concentrations between 0 to $500 \mu \mathrm{g} \mathrm{ml}^{-1}$ were used. For set B, fixed concentrations of WSPFE EAF used were 0.2 $\mu \mathrm{g} \mathrm{ml} \mathrm{m}^{-1}$ and $200 \mu \mathrm{g} \mathrm{ml}{ }^{-1}$ for AChE and BChE enzymatic assays respectively, also chosen on the basis of the respective $\mathrm{IC}_{50}$ values. $\mathrm{DH}$ in varying concentrations between 0 to $500 \mu \mathrm{g} \mathrm{ml}^{-1}$ were used.

\section{Statistical Analyses}

Statistical analyses were performed using SPSS Statistics (IBM Corporation, Armonk, New York, USA). Analysis of variance (ANOVA), repeated measures or one-way where appropriate, with Tukey's HSD (honestly significant difference) posthoc test were performed and differences with $p$ values of less than 0.05 were considered statistically significant. Pearson's correlation analysis was performed to correlate the total phenolic content and ChE inhibition in the WSPFE samples. $\mathrm{IC}_{50}$ values were calculated using the Quest $\mathrm{Graph}^{\mathrm{TM}}$ $\mathrm{IC}_{50}$ Calculator (AAT Bioquest, Inc., Sunnyvale, CA, USA) (AAT Bioquest, 2019). AChE Selectivity Index (SI) values were calculated in Microsoft Excel (Microsoft Corporation, Redmond, WA, USA) using the formula: $\mathrm{AChE} \mathrm{SI}=\mathrm{IC}_{50}$ of $\mathrm{BChE} / \mathrm{IC}_{50}$ of $\mathrm{AChE}$ (Zhao et al., 2013).

\section{RESULTS AND DISCUSSION}

Cholinergic nerves are a major portion of the central, as well as peripheral parasympathetic and sympathetic nervous systems (Craig et al., 2011). The main pathogenic feature connected with the progression of Alzheimer's disease is the weakening 
of the brain cholinergic system. ChE inhibitors are recognised as one of the choices in treating Alzheimer's disease, approved as a therapeutic strategy to reduce symptoms and prevent its progression (Hussein et al., 2018).

The neuroprotective effects attributed to plant phenolic compounds could be mediated by their AChE inhibitory activities, in addition to other mechanisms of action, such as antioxidant, anti-inflammatory and anti-amyloid production activities, as well as interactions with brain cell signalling (Nwidu et al., 2017; Szwajgier et al., 2017; 2018). Among plant phenolic compounds, the pharmacokinetic properties of phenolic acids make them suitable drugs for Alzheimer's disease, owing to their simplicity and structural similarity to popular ChE inhibitors (Szwajgier et al., 2018). They are not degraded in the gastrointestinal tract prior to absorption (Rechner et al., 2002), easily released from foods in the gastrointestinal tract by bacterial esterases and directly absorbed (Rondini et al., 2002), as well as being transformed only to a limited extent (Couteau et al., 2001).
The majority of phenolic compounds present in WSPFE are phenolic acids. In the present study, seven preparative liquid chromatographic fractions (F1-F7) of WSPFE were prepared based on information obtained from previous literature on WSPFE (Figure 1). F1 contained shikimic acid (Sambandan et al., 2011), F3 contained protocatechuic acid (Sambanthamurthi et al., 2011), F4 contained p-hydroxybenzoic acid (Sambanthamurthi et al., 2011), F5 contained an indoleacetic acid derivative (Sambanthamurthi et al., 2014), while F6 contained three caffeoylshikimic acid isomers (Sambanthamurthi et al., 2011). The components of F2 and F7 are still unknown.

Total phenolic content analysis of these samples at $5000 \mu \mathrm{g} \mathrm{ml}^{-1}$ (Figure 2) showed that SD WSPFE had a higher total phenolic content compared to FD WSPFE $(p<0.05)$. This was similar to a previous study in which higher chokeberry polyphenol levels were present after drying at high temperatures, compared to after freeze drying (Horszwald et al., 2013). SD papaya products also retained higher levels of flavonoids and phenolic compounds compared to

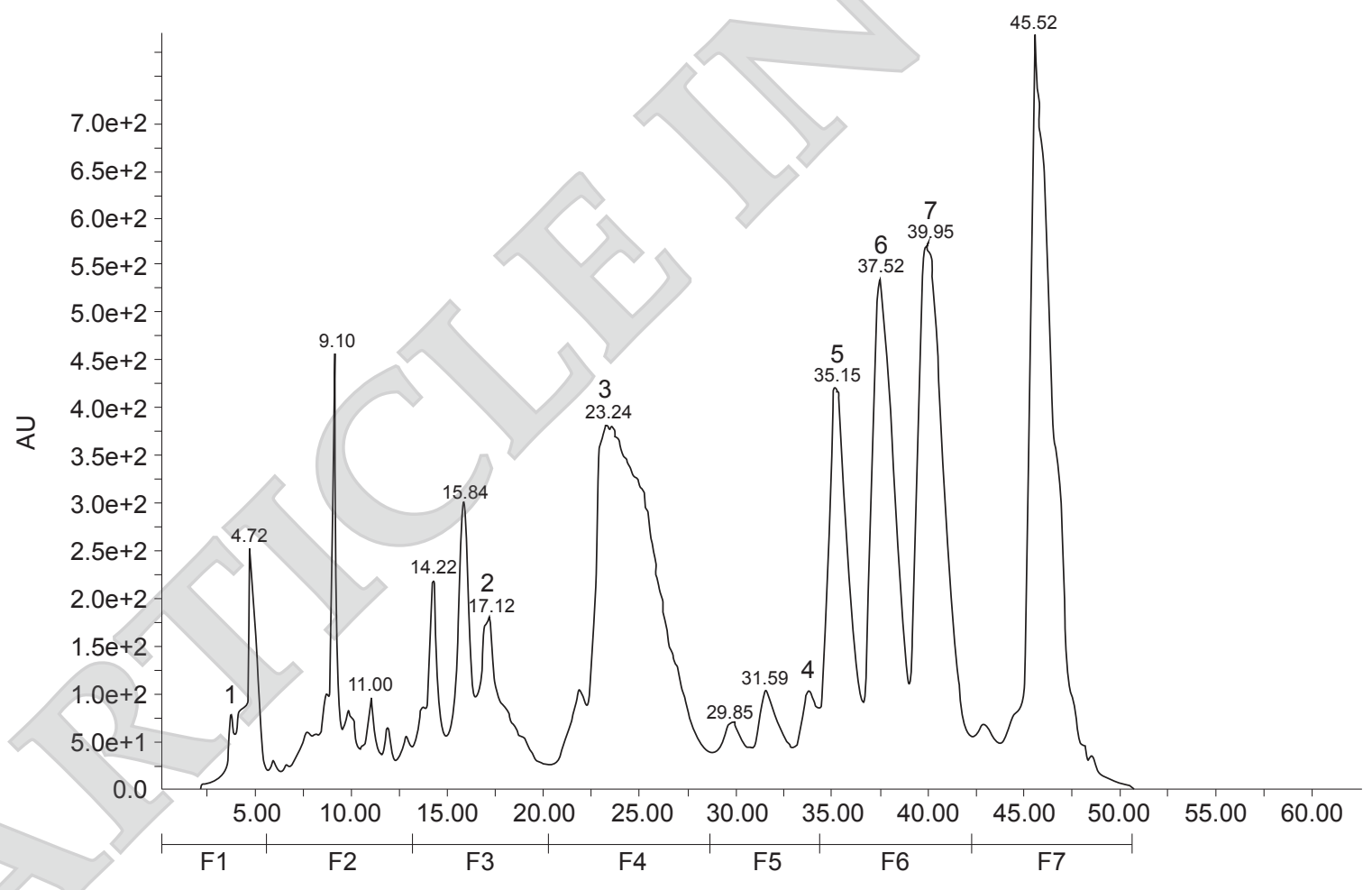

Note: The different Water-Soluble Palm Fruit Extract (WSPFE) fractions (F1-F7) were prepared using a Waters Preparative AutoPurification High Performance Liquid Chromatography (HPLC) System (Waters Corporation, Milford, MA, USA). Stationary phase: Reverse phase Waters Atlantis C18 $5 \mu \mathrm{m}$ column (Waters Corporation, Milford, MA, USA). Mobile phase: Binary gradient system, with phase A comprising distilled water containing 0.02\% (v/v) trifluoroacetic acid and phase B comprising 70\%:30\% (v/v) methanolacetonitrile. Flow rate: $20 \mathrm{ml} \mathrm{min} \mathrm{mi}^{-1}$. Pressure limit: $2.76 \times 10^{4} \mathrm{kPa}$. Total run time: $55 \mathrm{~min}$. Gradient elution: Started from 100\% (v/v) phase A and $0 \%(\mathrm{v} / \mathrm{v})$ phase B, increased to $32.5 \%(\mathrm{v} / \mathrm{v})$ phase B over $40 \mathrm{~min}$, then increased to $62.5 \%(\mathrm{v} / \mathrm{v})$ phase B over 6 min and finally decreased to $0 \%(\mathrm{v} / \mathrm{v})$ phase B over $9 \mathrm{~min}$. Detection: Ultraviolet/visible (UV/VIS) at $280 \mathrm{~nm}$ UV wavelength. Peaks: 1: Shikimic acid; 2: Protocatechuic acid; 3: $p$-hydroxybenzoic acid; 4: Indoleacetic acid derivative; 5: 5-O-caffeoylshikimic acid; 6 : 3-O-caffeoylshikimic acid; 7: 4-O-caffeoylshikimic acid. 


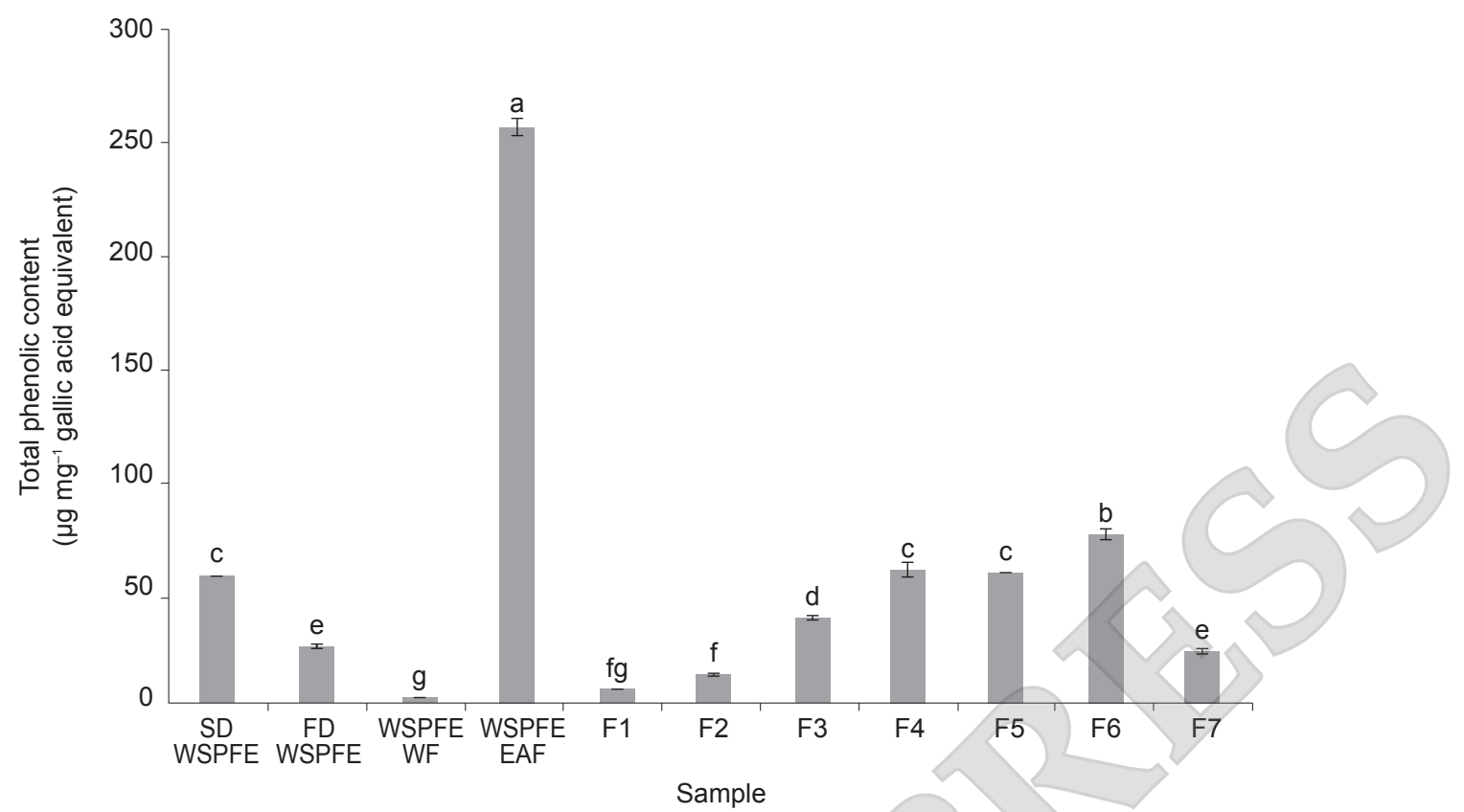

Note: Values are means \pm standard error of the mean (SEM) from triplicate determinations. Means with different letters are significantly different $(p<0.05)$ by one-way analysis of variance (ANOVA) with Tukey's honestly significant difference (HSD) post-hoc test. WSPFE - Water-Soluble Palm Fruit Extract; EAF - ethyl acetate fraction; WF - water fraction; SD - spray dried; FD - freeze dried.

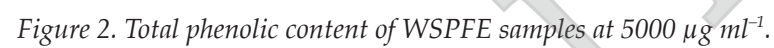

FD products (Gomes et al., 2018). Drying is a major food processing operation to increase shelf life. The choice of drying method influences product quality, as it is related to the retention of bioactive compounds and antioxidant activities (Abascal et al., 2005). Freeze drying is a technique based on water removal by sublimation under low pressure and is used to obtain various industrial products (Santo et al., 2013). It makes a product lightweight, prevents yeast and bacteria survival, as well as retainsits taste, shape and appearance when water is reintroduced. However, freeze drying equipment is expensive, while the process is very time-consuming and labour-intensive. Conversely, spray drying removes moisture from products by rapid evaporation on spray droplet under high temperature exposure. Spray drying produces a dry powder from a liquid or slurry by rapidly drying with a hot gas in a single processing step. Spray drying is suitable for heatsensitive materials, despite the high temperatures of the drying gas, owing to the cooling effect of the evaporating solvent which keeps the droplet temperature relatively low (Haggag and Faheem, 2015). The heat and mass transfer occurs in the air with vapour films surrounding the product droplets, which form protective envelopes to keep product particles from approaching the dryer outlet temperature. Spray drying also has high performance due to low residence time of a few seconds (Verma and Singh, 2015).

In the present study, fractionation of liquid WSPFE with ethyl acetate resulted in WSPFE EAF which had the highest total phenolic content among all of the WSPFE samples, with the remaining components in WSPFE WF having the least. WSPFE EAF had a total phenolic content of around 25\%. The total phenolic content of the WSPFE fractions increased from F1 to F6, but dipped down in F7, i.e. the total phenolic content of the WSPFE fractions followed the ascending order of F1 $<\mathrm{F} 2<\mathrm{F} 7<\mathrm{F} 3<$ $\mathrm{F} 5<\mathrm{F} 4<\mathrm{F} 6$. Initial comparison of whole WSPFE, i.e. SD WSPFE and FD WSPFE, showed that SD WSPFE had higher AChE and BChE inhibition activities compared to FD WSPFE, while WSPFE EAF had higher $\mathrm{AChE}$ and $\mathrm{BChE}$ inhibition activities compared to WSPFE WF (Figure 3). Although these results appeared to reflect the total phenolic content of the samples, in which samples with higher total phenolic content had higher AChE and BChE inhibition activities, there was weak positive correlation between the total phenolic content of all the WSPFE samples with AChE $\left(R^{2}=0.527, p>0.05\right)$ and $\mathrm{BChE}\left(\mathrm{R}^{2}=0.411, p>0.05\right)$ inhibition potential, which was in line with previous studies (Elufioye et al., 2019; Zengin et al., 2020). As the fractions used in the present study were not pure compounds, unidentified non-phenolic inhibitors might justify the activities observed. In addition, these findings might be due to the complex nature of these fractions and interactions between phytochemicals present in them.

Further AChE and BChE assays were then carried out using WSPFE samples of varying concentrations between 0 to $500 \mu \mathrm{g} \mathrm{ml}^{-1}$, alongside 

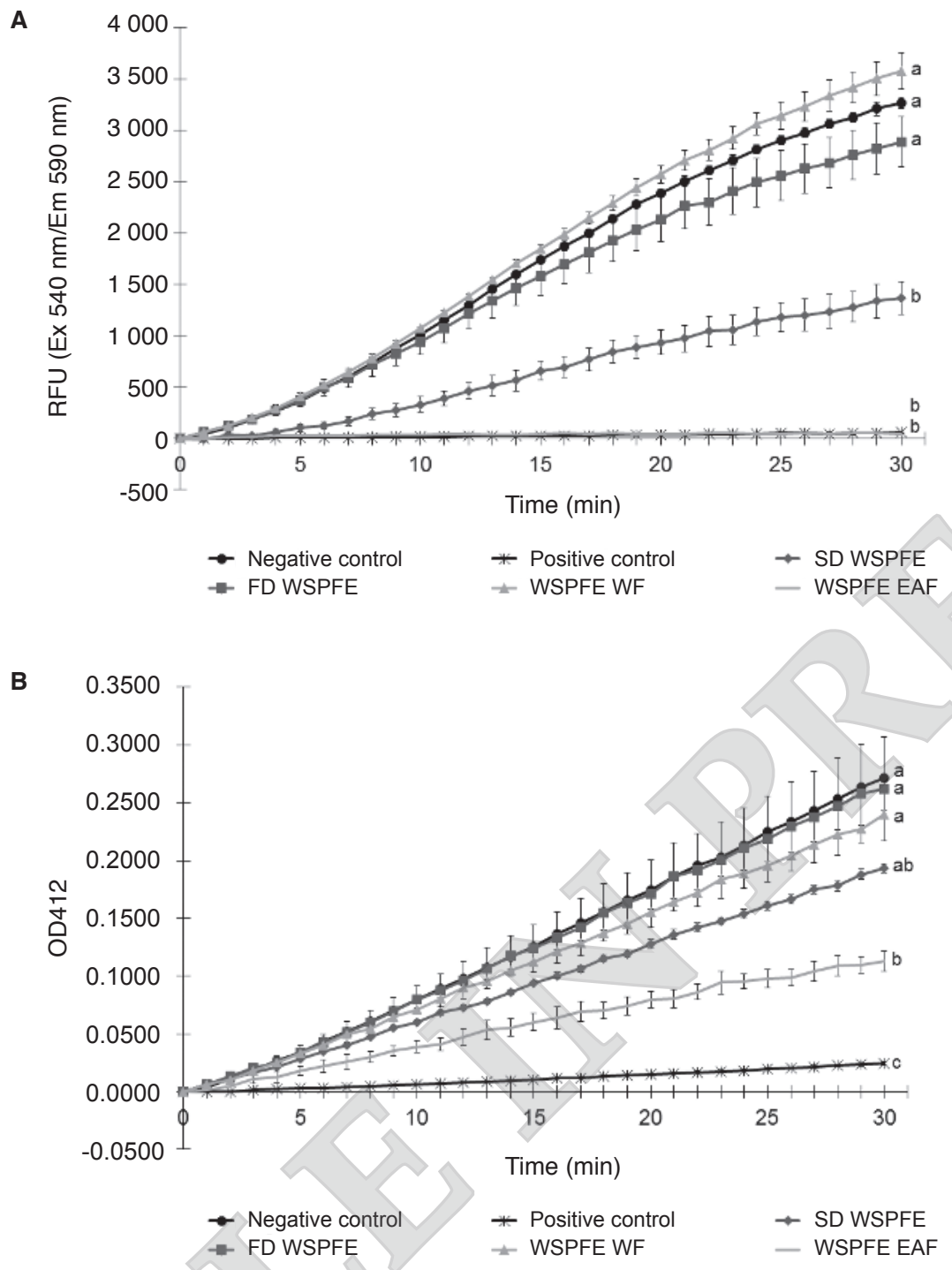

Note: Values are means \pm standard error of the mean (SEM) from triplicate determinations. Means with different letters are significantly different $(p<0.05)$ by repeated measures analysis of variance (ANOVA) with Tukey's honestly significant difference (HSD) posthoc test. AChE - acetylcholinesterase; BChE - butyrylcholinesterase; WSPFE - Water-Soluble Palm Fruit Extract; EAF - ethyl acetate fraction; WF - water fraction; SD - spray dried; FD - freeze dried.

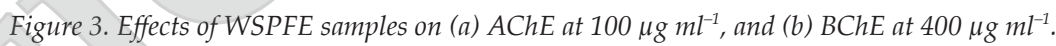

the positive control $\mathrm{DH}$, in order to obtain the $\mathrm{IC}_{50}$ values on the respective enzymes (Table 1). Based on the $\mathrm{IC}_{50}$ values determined, the inhibitory effects of WSPFE samples on AChE followed the ascending order of SD WSPFE $<$ F4 $<$ F2 $<$ F3 $<$ F5 $<$ F1 $<$ F6 $<$ F7 $<$ WSPFE EAF. The $\mathrm{IC}_{50}$ values of FD WSPFE and WSPFE WF were not achieved as they were higher than the highest concentration tested (500 $\left.\mu \mathrm{g} \mathrm{ml}^{-1}\right)$. For BChE, the inhibitory effects of WSPFE samples on this enzyme were not strong, since the $\mathrm{IC}_{50}$ values of several samples, i.e. SD WSPFE, FD WSPFE, WSPFE WF, F2, F6 and F7 were not achieved as they were higher than the highest concentration tested $\left(500 \mu \mathrm{g} \mathrm{ml}^{-1}\right)$. On the other hand, among the WSPFE samples of which their $\mathrm{IC}_{50}$ values were determined, their inhibitory effects on $\mathrm{BChE}$ followed the ascending order of $\mathrm{F} 4<\mathrm{F} 1<\mathrm{F} 5$
$<$ F3 $<$ WSPFE EAF. Hence, in both assays, WSPFE EAF showed the highest inhibitory activities (AChE $\mathrm{IC}_{50}: 0.218 \pm 0.029 \mu \mathrm{g} \mathrm{ml}^{-1} ; \mathrm{BChE} \mathrm{IC}_{50}: 222.860 \pm 5.777$ $\left.\mu \mathrm{g} \mathrm{ml}^{-1}\right)$. However, the positive control DH still had lower $\mathrm{IC}_{50}$ values $\left(\mathrm{AChE} \mathrm{IC} \mathrm{I}_{50}: 0.013 \pm 0.001 \mu \mathrm{g} \mathrm{ml}^{-1}\right.$, $\mathrm{BChE} \mathrm{IC}_{50}: 19.820 \pm 1.415 \mu \mathrm{g} \mathrm{ml}^{-1}$ ) and hence higher inhibitory potency when compared to WSPFE EAF.

AChE selectivity index (SI) is defined as $\mathrm{IC}_{50}$ $\mathrm{BChE} / \mathrm{IC}_{50} \mathrm{AChE}$ ratio, with a higher $\mathrm{IC}_{50} \mathrm{BChE} /$ $\mathrm{IC}_{50}$ AChE ratio indicating a higher selectivity towards AChE rather than BChE. All of the WSPFE samples tested in the present study were found to be more AChE selective. AChE SI values calculated based on $\mathrm{IC}_{50}$ values which could be determined indicated that the AChE selectivity of the WSPFE samples followed the ascending order of F4 $<$ F3 $<$ F5 $<$ F1 $<$ WSPFE EAF. The AChE SI value of 
WSPFE EAF was 1022.294. This was lower than that of the AChE selective positive control DH, which had the highest AChE SI value of 1524.615. Two of the fractions, F4 and F3, which contained p-hydroxybenzoic acid and protocatechuic acid respectively, had the lowest AChE SI values (7.584 and 9.367 respectively), indicating that these fractions were less AChE selective compared to the other WSPFE samples tested and may thus, function better as dual ChE inhibitors. The samples F5 and F1 which contained an indoleacetic acid derivative and shikimic acid respectively, had AChE SI values of 27.879 and 38.897 respectively. F6 which contained three caffeoylshikimic acid isomers showed mainly AChE inhibitory properties.

Protocatechuic acid and $p$-hydroxybenzoic acid in particular have been shown to have potential neuroprotective properties (Winter et al., 2017). The amount of $p$-hydroxybenzoic acid present in plant extracts has been shown to be significantly correlated only with BChE inhibition (KobusCisowska et al., 2019a; 2019b). On the other hand, the amount of protocatechuic acid present in plant extracts was significantly correlated with both $\mathrm{AChE}$ and BChE inhibition (Kobus-Cisowska et al., $2019 b)$. In the present study however, we found that both fractions containing protocatechuic acid and $p$-hydroxybenzoic acid respectively demonstrated dual ChE inhibitory properties. This discrepancy might be because fractions and not pure compounds were used in the present study. Indoleacetic acid derivatives have been shown to have inhibitory activities against both AChE (Dileep et al., 2013) and BChE (Bodur and Cokugras, 2005) as well. Shikimic acid and caffeoylshikimic acids have not been shown to have ChE inhibitory activities as pure compounds, but plant extracts containing caffeoylshikimic acids and other shikimic acid derivatives possessing these properties have been documented in the literature (Kim et al., 2018; Song et al., 2020).

The possibility to isolate pure lead compounds from crude plant extracts or to administer these as nutraceuticals or cheap alternatives to drugs makes plants a versatile source of natural ChE inhibitors. However, plants produce a variety of secondary metabolites representing a complex mixture of compounds from several chemical classes. The action modes of most plant metabolites cannot be attributed to one single lead chemical compound, but to their pleiotropic effects (Wink, 2015). Hence, synergies within and between chemical groups of different compounds in plant extracts may take place and should thus, be considered (Kaufmann et al., 2016). In the present study, WSPFE EAF which contained all the seven WSPFE fractions had the strongest inhibitory effects on AChE and BChE. This suggests that the seven WSPFE fractions when given together have synergistic inhibitory effects against these enzymes and would work better in attenuating these enzymes compared to giving individual WSPFE fractions.

In order to identify whether WSPFE EAF has potential synergistic effects in inhibiting AChE or BChE when used in combination with $\mathrm{DH}$, we tested binary mixtures of these two compounds in the respective assays (Table 1). We found that adding $\mathrm{DH}$ to WSPFE EAF (AChE $\mathrm{IC}_{50}$ : $0.218 \pm$ $0.029 \mu \mathrm{g} \mathrm{ml}{ }^{-1}$; BChE $\mathrm{IC}_{50}: 222.860 \pm 5.777 \mu \mathrm{g} \mathrm{ml} \mathrm{m}^{-1}$ ) resulted in lower $\mathrm{IC}_{50}$ values of WSPFE EAF for both enzymes $\left(\mathrm{AChE} \mathrm{IC}_{50}: 0.041 \pm 0.013 \mu \mathrm{g} \mathrm{ml} \mathrm{m}^{-1}\right.$; BChE $\mathrm{IC}_{50}: 40.127 \pm 8.063 \mu \mathrm{g} \mathrm{ml}^{-1}$ ), but only the differences for BChE were statistically significant $(p<0.05)$. However, the AChE SI values were almost similar (WSPFE EAF: 1022.294; DH + WSPFE EAF doses: 978.707), indicating that BChE/AChE selectivity was maintained. Adding WSPFE EAF to DH (AChE $\mathrm{IC}_{50}: 0.013 \pm 0.001 \mu \mathrm{g} \mathrm{ml}^{-1} ; \mathrm{BChE} \mathrm{IC}_{50}: 19.820 \pm 1.415$ $\mu \mathrm{g} \mathrm{m} \mathrm{m}^{-1}$ ) also resulted in lower $\mathrm{IC}_{50}$ values of $\mathrm{DH}$ for both enzymes (AChE $\mathrm{IC}_{50}: 0.008103 \pm 0.000174$

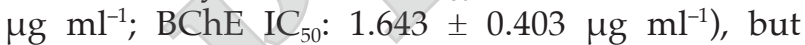
these differences were not statistically significant $(p>0.05)$. Nevertheless, the AChE SI value was 7.5fold lower (DH: 1524.615; WSPFE EAF + DH doses: 202.764), indicating that $\mathrm{BChE} / \mathrm{AChE}$ selectivity was higher.

Hence, although WSPFE EAF by itself had high AChE selectivity, it reduced rather than increased the AChE selectivity of DH. A previous study showed that phenformin with an AChE SI value of 0.052 indicating that it was BChE selective did not alter the AChE SI value of donepezil, whereas a metformin sulphonamide derivative with an AChE SI value of 3.23 increased the AChE SI value of donepezil around 200-fold higher. On the other hand, metformin with an AChE SI value of $>425.53$ did not alter the AChE SI value of donepezil either (Markowicz-Piasecka et al., 2018). Many factors may thus, be at work for this apparent discrepancy. The exact mechanism by which synergistic effects could be achieved could only be explained by conducting combination index-isobologram analysis and enzyme kinetic studies (Balkrishna et al., 2019; Huang et al., 2019; Kaufmann et al., 2016). In silico molecular docking experiments would also be helpful to identify the molecular mechanistics of AChE and BChE inhibition by the compounds present in WSPFE, as well as the structure-activity relationships of individual compounds with these ChEs (Jang et al., 2018).

A limitation of the present study is that the bioavailability and biotransformation of most of the phenolic compounds in WSPFE and their metabolites are unknown at the moment. This information must be considered and applied, as metabolism is important in defining actual activity. Drugs that cross the blood brain barrier do not have dissociable groups (Tayeb et al., 2012). Increasing 
TABLE 1. THE IC $_{50}$ AND SELECTIVITY INDEX (SI) VALUES OF WSPFE SAMPLES AS WELL AS BINARY MIXTURES OF WSPFE EAF AND DH AGAINST AChE AND BChE

\begin{tabular}{|c|c|c|c|}
\hline \multirow{2}{*}{ Sample } & \multicolumn{2}{|c|}{$\mathrm{IC}_{50}\left(\mu \mathrm{g} \mathrm{ml}^{-1}\right)$} & \multirow{2}{*}{ AChE SI } \\
\hline & $\mathrm{AChE}$ & BChE & \\
\hline SD WSPFE & $110.177 \pm 7.141^{a}$ & $>500$ & * \\
\hline FD WSPFE & $>500$ & $>500$ & * \\
\hline WSPFE WF & $>500$ & $>500$ & * \\
\hline WSPFE EAF & $0.218 \pm 0.029^{d}$ & $222.860 \pm 5.777^{\mathrm{d}}$ & 1022.294 \\
\hline $\mathrm{F} 1$ & $9.903 \pm 1.751^{\mathrm{cd}}$ & $385.193 \pm 11.966^{\mathrm{ab}}$ & 38.897 \\
\hline $\mathrm{F} 2$ & $37.093 \pm 7.439^{b}$ & $>500$ & \\
\hline F3 & $33.530 \pm 3.131^{b c}$ & $314.087 \pm 10.251^{\mathrm{c}}$ & \\
\hline $\mathrm{F} 4$ & $53.393 \pm 11.972^{\mathrm{b}}$ & $404.913 \pm 12.793^{\mathrm{a}}$ & \\
\hline F5 & $12.197 \pm 2.038^{\mathrm{cd}}$ & $340.043 \pm 24.633^{b c}$ & \\
\hline F6 & $3.327 \pm 0.052^{\mathrm{d}}$ & $>500$ & \\
\hline F7 & $0.645 \pm 0.283^{\mathrm{d}}$ & $>500$ & \\
\hline $\mathrm{DH}$ & $0.013 \pm 0.001^{\mathrm{d}}$ & $19.820 \pm 1.415^{\mathrm{e}}$ & 1524.615 \\
\hline DH + WSPFE EAF doses (set A) & $0.041 \pm 0.013^{\mathrm{d}}$ & $40.127 \pm 8.063^{e}$ & 978.707 \\
\hline WSPFE EAF + DH doses (set B) & $0.008103 \pm 0.000174^{\mathrm{d}}$ & $1.643 \pm 0.403^{e}$ & 202.764 \\
\hline
\end{tabular}

Note: $\mathrm{The}_{\mathrm{IC}}$ indicates the dose that induced a $50 \%$ enzymatic inhibition as compared to negative control (enzyme only) over $30 \mathrm{~min}$. These $\mathrm{IC}_{50}$ values were expressed as means \pm standard error of the mean (SEM) from triplicate determinations. Means in a column with different letters are significantly different $(p<0.05)$ by one-way analysis of variance (ANOVA) with Tukey's honestly significant difference (HSD) post-hoc test. $>500$ indicates $\mathrm{IC}_{50}$ was not achieved as it was higher than the highest concentration tested $\left(500 \mu \mathrm{g} \mathrm{ml}^{-1}\right)$. AChE SI is the $\mathrm{AChE}$ selectivity index defined as $\mathrm{IC}_{50} \mathrm{BChE} /$ $\mathrm{IC}_{50}$ AChE ratio. * indicates AChE SI was not calculated. AChE - acetylcholinesterase; BChE - butyrylcholinesterase; WSPFE - Water-Soluble Palm Fruit Extract; EAF - ethyl acetate fraction; DH - donepezil hydrochloride; WF - water fraction; SD - spray dried; FD - freeze dried.

the availability of $\mathrm{ACh}$ at receptors in the brain would result in better neuron to neuron transport. However, the poor ability to cross the blood brain barrier can be an advantage when a compound to regulate the peripheral nervous system is needed (Pohanka, 2014), such as in the treatment of myasthenia gravis (Benatar and Kaminski, 2012) and in post-anaesthesia (Chambers et al., 2010). While direct measurements have not been done to confirm the availability of WSPFE in the brain, a previous study confirmed the increased expression of tyrosine hydroxylase in the brains of Nile rats fed WSPFE (Weinberg et al., 2019). In addition, the bioavailability of two of the components present in WSPFE, i.e. protocatechuic acid and $p$-hydroxybenzoic acid, has been indicated before in the literature. Protocatechuic acid has been found to be the major human plasma metabolite of cyanidin-glucosides following oral consumption of blood orange juice (Vitaglione et al., 2007), while $p$-hydroxybenzoic acid is the major human plasma metabolite of pelargonidin-glucosides following oral consumption of strawberries (Azzini et al., 2010). However, while protocatechuic acid has been found to be present in the brain following oral supplementation in animals (Lin et al., 2011), p-hydroxybenzoic acid was not (Margalef et al., 2015). Hence, understanding the bioavailability of WSPFE components in either the central or peripheral nervous system would further help to determine the applications of the ChE inhibition properties of WSPFE samples found in the present study.

\section{CONCLUSION}

SD WSPFE had higher AChE and BChE inhibition activities compared to FD WSPFE. WSPFE EAF was found to possess the highest inhibitory activities against these enzymes and the highest AChE selectivity among all the WSPFE samples compared, but these effects were weaker than those of the positive control DH. Fractions containing $p$-hydroxybenzoic acid and protocatechuic acid had the lowest AChE selectivity indices and may thus, function as dual ChE inhibitors. Binary mixtures of DH and WSPFE EAF might have more potent inhibitory effects against these enzymes, as well as higher BChE/AChE selectivity. Further studies, especially in vivo ones, to further confirm the in vitro results obtained in the present study are warranted. 


\section{ACKNOWLEDGEMENT}

The authors thank the Director-General of MPOB for permission to publish these results. They also thank the support staff from MPOB who provided technical assistance in various parts of the study, namely Mohamad Daniel Noorazmi for technical assistance in preparing liquid WSPFE, as well as Wan Saridah Wan Omar and Jabariah Md Ali for technical assistance in preparing the FD WSPFE samples and fractions, in addition to carrying out the enzymatic assays. This project was funded by MPOB and the Eleventh Malaysia Plan (RMK-11) PROFENOLIS (2011101805) budget.

\section{REFERENCES}

AAT Bioquest (2019). Quest Graph ${ }^{\mathrm{TM}} \mathrm{IC}_{50}$ calculator. https:/ / www.aatbio.com/tools/ic50-calculator, 19 February 2021.

Abascal, K; Ganora, L and Yarnell, E (2005). The effect of freeze-drying and its implications for botanical medicine: A review. Phytother. Res., 19(8): 655-660.

Adewusi, E A and Steenkamp, V (2011). In vitro screening for acetylcholinesterase inhibition and antioxidant activity of medicinal plants from southern Africa. Asian Pac. J. Trop. Med., 4(10): 829-835.

Allgaier, M and Allgaier, C (2014). An update on drug treatment options of Alzheimer's disease. Front. Biosci. (Landmark Ed.), 19: 1345-1354.

Arbel, Y; Shenhar-Tsarfaty, S; Waiskopf, N; Finkelstein, A; Halkin, A; Revivo, M; Berliner, S; Herz, I; Shapira, I; Keren, G; Soreq, H and Banai, S (2014). Decline in serum cholinesterase activities predicts 2-year major adverse cardiac events. Mol. Med., 20: 38-45.

Augustin, N; Nuthakki, V K; Abdullaha, M; Hassan, Q P; Gandhi, S G and Bharate, S B (2020). Discovery of helminthosporin, an anthraquinone isolated from Rumex abyssinicus Jacq. as a dual cholinesterase inhibitor. ACS Omega, 5(3): 1616-1624.

Azzini, E; Vitaglione, P; Intorre, F; Napolitano, A; Durazzo, A; Foddai, M S; Fumagalli, A; Catasta, G; Rossi, L; Venneria, E; Raguzzini, A; Palomba, L; Fogliano, V and Maiani, G (2010). Bioavailability of strawberry antioxidants in human subjects. Br. J. Nutr., 104(8): 1165-1173.

Balkrishna, A; Pokhrel, S; Tomer, M; Verma, S; Kumar, A; Nain, P; Gupta, A and Varshney, A (2019). Anti-acetylcholinesterase activities of mono-herbal extracts and exhibited synergistic effects of the phytoconstituents: A biochemical and computational study. Molecules, 24(22): 4175. DOI: 10.3390 / molecules 24224175 .

Benatar, M and Kaminski, H (2012). Medical and surgical treatment for ocular myasthenia. Cochrane Database Syst. Rev., 12: CD005081. DOI: 10.1002/14651858.CD005081.pub3.

Bodur, E and Cokugras, A N (2005). The effects of indole-3-acetic acid on human and horse serum butyrylcholinesterase. Chem-Biol. Interact., 157-158: 375-378.

Chambers, D; Paulden, M; Paton, F; Heirs, M; Duffy, S; Craig, D; Hunter, J; Wilson, J; Sculpher, M and Woolacott, N (2010). Sugammadex for the reversal of muscle relaxation in general anaesthesia: A systematic review and economic assessment. Health Technol. Assess., 14(39): 1-211.

Colovic, M B; Krstic, D Z; Lazarevic-Pasti, T D; Bondzic, A M and Vasic, V M (2013). Acetylcholinesterase inhibitors: Pharmacology and toxicology. Curr. Neuropharmacol., 11(3): 315-335.

Couteau, D; Mccartney, A L; Gibson, G R; Williamson, G and Faulds, C B (2001). Isolation and characterization of human colonic bacteria able to hydrolyse chlorogenic acid. J. Appl. Microbiol., 90(6): 873-881.

Craig, L A; Hong, N S and Mcdonald, R J (2011). Revisiting the cholinergic hypothesis in the development of Alzheimer's disease. Neurosci. Biobehav. Rev., 35(6): 1397-1409.

Davies, P and Maloney, A J (1976). Selective loss of central cholinergic neurons in Alzheimer's disease. Lancet, 2(8000): 1403. DOI: 10.1016/s01406736(76)91936-x.

Dileep, K V; Remya, C; Tintu, I and Sadasivan, C (2013). Inhibition, ADME and structure based modification of IAA and IBA against acetylcholinesterase: An attempt towards new drug development for Alzheimer's disease. Front. Life Sci., 7(3-4): 164-173.

Eldufani, J and Blaise, G (2019). The role of acetylcholinesterase inhibitors such as neostigmine and rivastigmine on chronic pain and cognitive function in aging: A review of recent clinical applications. Alzheimers Dement. (N Y), 5: 175-183.

Elufioye, T O; Chinaka, C G and Oyedeji, A O (2019). Antioxidant and anticholinesterase activities of Macrosphyra longistyla (DC) Hiern relevant in the 
management of Alzheimer's disease. Antioxidants (Basel), 8(9): 400. DOI: $10.3390 /$ antiox8090400.

Ferreira, A; Proenca, C; Serralheiro, M L and Araujo, M E (2006). The in vitro screening for acetylcholinesterase inhibition and antioxidant activity of medicinal plants from Portugal. J. Ethnopharmacol., 108(1): 31-37.

Gao, X; Ohlander, M; Jeppsson, N; Bjork, L and Trajkovski, V (2000). Changes in antioxidant effects and their relationship to phytonutrients in fruits of sea buckthorn (Hippophae rhamnoides L.) during maturation. J. Agric. Food Chem., 48(5): 1485-1490.

Garcia-Ayllon, M S; Small, D H; Avila, J and Saez-Valero, J (2011). Revisiting the role of acetylcholinesterase in Alzheimer's disease: Crosstalk with P-tau and beta-amyloid. Front. Mol. Neurosci., 4: 22. DOI: 10.3389/fnmol.2011.00022.

Gomes, W F; Franca, F R M; Denadai, M; Andrade, J K S; Da Silva Oliveira, E M; De Brito, E S; Rodrigues, $S$ and Narain, N (2018). Effect of freeze- and spraydrying on physico-chemical characteristics, phenolic compounds and antioxidant activity of papaya pulp. J. Food Sci. Technol., 55(6): 2095-2102.

Greig, N H; Utsuki, T; Ingram, D K; Wang, Y; Pepeu, G; Scali, C; Yu, Q S; Mamczarz, J; Holloway, H W; Giordano, T; Chen, D; Furukawa, K; Sambamurti, K; Brossi, A and Lahiri, D K (2005). Selective butyrylcholinesterase inhibition elevates brain acetylcholine, augments learning and lowers Alzheimer beta-amyloid peptide in rodent. Proc. Natl. Acad. Sci. USA, 102(47): 17213-17218.

Haggag, Y A and Faheem, A M (2015). Evaluation of nano spray drying as a method for drying and formulation of therapeutic peptides and proteins. Front. Pharmacol., 6: 140. DOI: 10.3389/ fphar.2015.00140.

Horszwald, A; Julien, H and Andlauer, W (2013). Characterisation of Aronia powders obtained by different drying processes. Food Chem., 141(3): 28582863.

Huang, R Y; Pei, L; Liu, Q; Chen, S; Dou, H; Shu, G; Yuan, Z X; Lin, J; Peng, G; Zhang, W and Fu, H (2019). Isobologram analysis: A comprehensive review of methodology and current research. Front. Pharmacol., 10: 1222. DOI: 10.3389/ fphar.2019.01222.

Hussein, W; Saglik, B N; Levent, S; Korkut, B; Ilgin, S; Ozkay, Y and Kaplancikli, Z A (2018). Synthesis and biological evaluation of new cholinesterase inhibitors for Alzheimer's disease. Molecules, 23(8): 2033. DOI: 10.3390 / molecules23082033.
Jabir, N R; Khan, F R and Tabrez, S (2018). Cholinesterase targeting by polyphenols: A therapeutic approach for the treatment of Alzheimer's disease. CNS Neurosci. Ther., 24(9): 753-762.

Jang, C; Yadav, D K; Subedi, L; Venkatesan, R; Venkanna, A; Afzal, S; Lee, E; Yoo, J; Ji, E; Kim, S Y and Kim, M H (2018). Identification of novel acetylcholinesterase inhibitors designed by pharmacophore-based virtual screening, molecular docking and bioassay. Sci. Rep., 8(1): 14921. DOI: 10.1038/ s41598-018-33354-6.

Kadiyala, M; Ponnusankar, S and Elango, K (2014). Screening of siddha medicinal plants for its in vitro acetylcholinesterase and butyrylcholinesterase inhibitory activity. Pharmacogn. Mag., 10(Suppl 2): S294-S298.

Kaufmann, D; Kaur Dogra, A; Tahrani, A; Herrmann, F and Wink, M (2016). Extracts from traditional Chinesemedicinal plantsinhibitacetylcholinesterase, a known Alzheimer's disease target. Molecules, 21(9): 1161. DOI: $10.3390 /$ molecules21091161.

Khan, H; Marya; Amin, S; Kamal, M A and Patel, S (2018). Flavonoids as acetylcholinesterase inhibitors: Current therapeutic standing and future prospects. Biomed. Pharmacother., 101: 860-870.

Kim, M S; Lee, D Y; Sung, S H and Jeon, W K (2018). Anti-cholinesterase activities of hydrolysable tannins and polyhydroxytriterpenoid derivatives from Terminalia chebula Retz. fruit. Rec. Nat. Prod., 12(3): 284-289.

Kobus-Cisowska, J; Szymanowska-Powalowska, D; Szczepaniak, O; Kmiecik, D; Przeor, M; GramzaMichalowska, A; Cielecka-Piontek, J; Smuga-Kogut, $\mathrm{M}$ and Szulc, P (2019a). Composition and in vitro effects of cultivars of Humulus lupulus L. Hops on cholinesterase activity and microbial growth. Nutrients, 11(6): 1377. DOI: 10.3390/nu11061377.

Kobus-Cisowska, J; Szymanowska, D; Maciejewska, P; Kmiecik , D; Gramza-Michałowska, A; Kulczyński, B and Cielecka-Piontek, J (2019b). In vitro screening for acetylcholinesterase and butyrylcholinesterase inhibition and antimicrobial activity of chia seeds (Salvia hispanica). Electron. J. Biotechnol., 37: 1-10. DOI: 10.1016/j.ejbt.2018.10.002.

Kumaran, K R; Ahada, M A; Rawab, M S A; Wahabb, $\mathrm{H}$ and Hassan, Z (2019). Potential Malaysian medicinal plants for the treatment of Alzheimer's disease. Aust. Herb. Insight, 1(4): 22-27.

Kushairi, A; Ong-Abdullah, M; Nambiappan, B; Hishamuddin, E; Bidin, M N I Z; Ghazali, R; 
Subramaniam, V; Sundram, S and Parveez, G K A (2019). Oil palm economic performance in Malaysia and R\&D progress in 2018. J. Oil Palm Res., 31(2): 165-194.

Leow, S S; Sekaran, S D; Tan, Y A; Sundram, K and Sambanthamurthi, R (2013). Oil palm phenolics confer neuroprotective effects involving cognitive and motor functions in mice. Nutr. Neurosci., 16(5): 207-217.

Lin, C Y; Tsai, S J; Huang, C S and Yin, M C (2011). Antiglycative effects of protocatechuic acid in the kidneys of diabetic mice. J. Agric. Food Chem., 59(9): 5117-5124.

Margalef, M; Pons, Z; Iglesias-Carres, L; Bravo, F I; Muguerza, B and Arola-Arnal, A (2015). Lack of tissue accumulation of grape seed flavanols after daily long-term administration in healthy and cafeteria-diet obese rats. J. Agric. Food Chem., 63(45): 9996-10003.

Markowicz-Piasecka, M; Huttunen, K M and Sikora, J (2018). Metformin and its sulphonamide derivative simultaneously potentiate anti-cholinesterase activity of donepezil and inhibit beta-amyloid aggregation. J. Enzyme Inhib. Med. Chem., 33(1): 1309 1322.

Mathew, M and Subramanian, S (2014). In vitro screening for anti-cholinesterase and antioxidant activity of methanolic extracts of ayurvedic medicinal plants used for cognitive disorders. PLoS ONE, 9(1): e86804. DOI: 10.1371/journal.pone.0086804.

Nino, J; Hernandez, J A; Correa, Y M and Mosquera, $\mathrm{O} \mathrm{M}$ (2006). In vitro inhibition of acetylcholinesterase by crude plant extracts from Colombian flora. Mem. Inst. Oswaldo Cruz, 101(7): 783-785.

Nordberg, A; Ballard, C; Bullock, R; DarrehShori, T and Somogyi, M (2013). A review of butyrylcholinesterase as a therapeutic target in the treatment of Alzheimer's disease. Prim. Care Companion CNS Disord., 15(2): PCC. 12r01412. DOI: 10.4088 / PCC.12r01412.

Nuria, M C; Suganda, A G; Sukandar, E Y and Insanu, M (2020). Acetylcholinesterase: Inhibitory activity of some Indonesian vegetables and fraction of selected plants. J. Appl. Pharm. Sci., 10(1): 101-107.

Nwidu, L L; Elmorsy, E; Thornton, J; Wijamunige, B; Wijesekara, A; Tarbox, R; Warren, A and Carter, W G (2017). Anti-acetylcholinesterase activity and antioxidant properties of extracts and fractions of Carpolobia lutea. Pharm. Biol., 55(1): 1875-1883.
Orhan, I; Sener, B; Choudhary, M I and Khalid, A (2004). Acetylcholinesterase and butyrylcholinesterase inhibitory activity of some Turkish medicinal plants. J. Ethnopharmacol., 91(1): 57-60.

Orhan, I; Aslan, S; Kartal, M; Sener, B and Husnu Can Baser, K (2008). Inhibitory effect of Turkish Rosmarinus officinalis L. on acetylcholinesterase and butyrylcholinesterase enzymes. Food Chem., 108(2): 663-668.

Pohanka, M (2011). Cholinesterases, a target of pharmacology and toxicology. Biomed. Pap. Med. Fac. Univ. Palacky Olomouc Czech Repub., 155(3): 219-229.

Pohanka, M (2014). Inhibitors of acetylcholinesterase and butyrylcholinesterase meet immunity. Int. J. Mol. Sci., 15(6): 9809-9825.

Rechner, A R; Kuhnle, G; Bremner, P; Hubbard, G P; Moore, K P and Rice-Evans, C A (2002). The metabolic fate of dietary polyphenols in humans. Free Radic. Biol. Med., 33(2): 220-235.

Rondini, L; Peyrat-Maillard, M N; Marsset-Baglieri, A and Berset, C (2002). Sulfated ferulic acid is the main in vivo metabolite found after short-term ingestion of free ferulic acid in rats. J. Agric. Food Chem., 50(10): 3037-3041.

Sambandan, T G; Rha, C K; Sambanthamurthi, R; Sinskey, A J; Tan, Y A; Sundram, K and Wahid, M B (2011). Compositions comprising shikimic acid obtained from oil palm-based materials and method of producing thereof. Malaysian Palm Oil Board. WIPO Patent Application WO 2011/159144.

Sambanthamurthi, R; Tan, Y A and Sundram, K (2008). Treatment of vegetation liquors derived from oil-bearing fruit. Malaysian Palm Oil Board. United States Patent US 7387802 B2.

Sambanthamurthi, R; Tan, Y A; Sundram, K; Abeywardena, M; Sambandan, T G; Rha, C; Sinskey, A J; Subramaniam, K; Leow, S S; Hayes, K C and Wahid, M B (2011). Oil palm vegetation liquor: A new source of phenolic bioactives. Br. J. Nutr., 106(11): 1655-1663.

Sambanthamurthi, R; Tan, Y A; Omar, W S W; Ali, J M; Sambandan, T G; Yang, M F; Rha, C K and Sinskey, A J (2014). Isolation of a novel bioactive compound obtained from oil palm base materials. Malaysian Palm Oil Board. WIPO Patent Application WO 2014/209100.

Santo, E F D E; Lima, L K F D; Torres, A P C; Oliveira, GD and Ponsano, EHG (2013). Comparison between 
freeze and spray drying to obtain powder Rubrivivax gelatinosus biomass. Food Sci. Technol., 33: 47-51.

Scheltens, P; Blennow, K; Breteler, M M; De Strooper, B; Frisoni, G B; Salloway, S and Van Der Flier, W M (2016). Alzheimer's disease. Lancet, 388(10043): 505517.

Schneider, L S; Mangialasche, F; Andreasen, N; Feldman, H; Giacobini, E; Jones, R; Mantua, V; Mecocci, P; Pani, L; Winblad, B and Kivipelto, M (2014). Clinical trials and late-stage drug development for Alzheimer's disease: An appraisal from 1984 to 2014. J. Intern. Med., 275(3): 251-283.

Sheeja Malar, D; Beema Shafreen, R; Karutha Pandian, S and Pandima Devi, K (2017). Cholinesterase inhibitory, anti-amyloidogenic and neuroprotective effect of the medicinal plant Grewia tiliaefolia - An in vitro and in silico study. Pharm. Biol., 55(1): 381-393.

Song, K; Sivanesan, I; Ak, G; Zengin, G; Cziaky, Z; Jeko, J; Rengasamy, K R; Lee, O N and Kim, D $\mathrm{H}$ (2020). Screening of bioactive metabolites and biological activities of calli, shoots, and seedlings of Mertensia maritima (L.) Gray. Plants (Basel), 9(11): 1551. DOI: $10.3390 /$ plants9111551.

Srivastava, A and Hunter, J M (2009). Reversal of neuromuscular block. Br. J. Anaesth., 103(1): 115-129.

Suganthy, N and Devi, K P (2016). In vitro antioxidant and anti-cholinesterase activities of Rhizophora mucronata. Pharm. Biol., 54(1): 118-129.

Szwajgier, D; Borowiec, K and Pustelniak, K (2017). The neuroprotective effects of phenolic acids: Molecular mechanism of action. Nutrients, 9(5): 477. DOI: $10.3390 /$ nu9050477.

Szwajgier, D; Baranowska-Wojcik, E and Borowiec, K (2018). Phenolic acids exert anticholinesterase and cognition-improving effects. Curr. Alzheimer Res., 15(6): 531-543.

Tappayuthpijarn, P; Sattaponpan, C; Sakpakdeecharoen, I and Ittharat, A (2012). Cholinesterase inhibitory and antioxidant activities of Thai traditional remedies potentially used for Alzheimer's disease. Thai J. East Asian Stud., 17(1): 18-25.

Tayeb, H O; Yang, H D; Price, B H and Tarazi, F I (2012). Pharmacotherapies for Alzheimer's disease: Beyond cholinesterase inhibitors. Pharmacol. Ther., 134(1): 8-25.

Tundis, R; Bonesi, M; Menichini, F and Loizzo, M $R$ (2016). Recent knowledge on medicinal plants as source of cholinesterase inhibitors for the treatment of dementia. Mini Rev. Med. Chem., 16(8): 605-618.

Verma, A and Singh, S V (2015). Spray drying of fruit and vegetable juices - A review. Crit. Rev. Food Sci. Nutr., 55(5): 701-719.

Vitaglione, P; Donnarumma, G; Napolitano, A; Galvano, F; Gallo, A; Scalfi, L and Fogliano, V (2007). Protocatechuic acid is the major human metabolite of cyanidin-glucosides. J. Nutr., 137(9): 2043-2048.

Weinberg, R P; Koledova, V V; Schneider, K; Sambandan, T G; Grayson, A; Zeidman, G; Artamonova, A; Sambanthamurthi, R; Fairus, S; Sinskey, A J and Rha, C (2018a). Palm fruit bioactives modulate human astrocyte activity in vitro altering the cytokine secretome reducing levels of TNFalpha, RANTES and IP-10. Sci. Rep., 8(1): 16423. DOI: 10.1038/ s41598-018-34763-3.

Weinberg, R P; Koledova, V V; Shin, H; Park, J H; Tan, Y A; Sinskey, A J; Sambanthamurthi, R and Rha, C (2018b). Oil palm phenolics inhibit the in vitro aggregation of beta-amyloid peptide into oligomeric complexes. Int. J. Alzheimers Dis., 2018: 7608038. DOI: $10.1155 / 2018 / 7608038$.

Weinberg, R P; Koledova, V V; Subramaniam, A; Schneider, K; Artamonova, A; Sambanthamurthi, R; Hayes, K C; Sinskey, A J and Rha, C (2019). Palm fruit bioactives augment expression of tyrosine hydroxylase in the nile grass rat basal ganglia and alter the colonic microbiome. Sci. Rep., 9(1): 18625. DOI: 10.1038/s41598-019-54461-y.

Wink, M (2015). Modes of action of herbal medicines and plant secondary metabolites. Medicines (Basel), 2(3): 251-286.

Winter, A N; Brenner, M C; Punessen, N; Snodgrass, M; Byars, C; Arora, Y and Linseman, D A (2017). Comparison of the neuroprotective and antiinflammatory effects of the anthocyanin metabolites, protocatechuic acid and 4-hydroxybenzoic acid. Oxid. Med. Cell Longev., 2017: 6297080. DOI: $10.1155 / 2017$ / 6297080.

Wszelaki, N; Kuciun, A and Kiss, A K (2010). Screening of traditional European herbal medicines for acetylcholinesterase and butyrylcholinesterase inhibitory activity. Acta Pharm., 60(1): 119-128.

Zengin, G; Sinan, K I; Mahomoodally, M F; Angeloni, S; Mustafa, A M; Vittori, S; Maggi, F and Caprioli, G (2020). Chemical composition, antioxidant and enzyme inhibitory properties of different extracts obtained from spent coffee ground and coffee silverskin. Foods, 9(6): 713. DOI: 10.3390 / foods9060713. 
Zhao, T; Ding, K M; Zhang, L; Cheng, X M; Wang, C H and Wang, Z T (2013). Acetylcholinesterase and butryrylcholinesterase inhibitory activities of $\beta$-carboline and quinoline alkaloids derivatives from the plants of genus Peganum. J. Chemistry: 717232. DOI: $10.1155 / 2013 / 717232$. 